\title{
Vozes da Diferença: tempo e transformação entre educadores populares em Pernambuco
}

\author{
Catarina Morawska \\ Universidade Federal de São Carlos, São Carlos, São Paulo, Brasil \\ E-mail: morawska-vianna@ufscar.br
}




\section{Resumo}

Neste artigo aproxima-se narrativas de educadores populares em Recife e Olinda, atuantes em organizações não governamentais nas décadas de 1990 e 2000, dos conceitos de "tempo de emaranhamento" de Achille Mbembe e "inscrições intersticiais da diferença cultural" de Homi Bhabha. Argumenta-se que os educadores eram incitados a falar de si a partir das noções de raça, gênero, sexualidade e cultura, criando espaços de enunciação em que se intercruzavam experiências passadas, presentes e futuras: tornavase assim mulher, negro, homossexual, artista, educador. Além de fazer ver um argumento particular sobre tempo e transformação entre educadores, o encontro do material de campo e da teoria pós-colonial também agencia uma série de bifurcações analíticas e, assim, elicia outro argumento, dessa vez sobre tempo e transformação nos textos antropológicos. Como com qualquer narrativa, a dos antropólogos não ocorre sem efeitos. Explora-se o tempo emergente nas histórias de vida contadas pelos educadores e nas trajetórias de vida analisadas por antropólogos.

Palavras-chave: Teoria Pós-colonial. Raça. Gênero. Sexualidade. Trajetória de Vida. Escrita Antropológica.

\section{Abstract}

In this article I put forth two analytical movements. First, I draw parallels between narratives of grassroots educators in Recife and Olinda, Achille Mbembe's "time of entanglement" and Homi Bhabha's "interstitial inscriptions of cultural difference". This encounter elicits an argument about time and transformation among educators: as they were encouraged to talk about themselves in terms of race, gender, sexuality and culture, past, present and future experiences were intertwined and, hence, they became a woman, a black person, a homosexual, an artist, an educator. The encounter of the ethnographic material with postcolonial theory also triggers a second analytical movement, by means of a series of bifurcations in which yet another argument is elicited on time and transformation in anthropological texts. As in any narrative, that of anthropologists does not occur without effect. Thus, I explore the emerging time in the life histories told by the educators and in the life trajectories analyzed by anthropologists.

Keywords: Postcolonial Theory. Race. Gender. Sexuality. Life Trajectory. Anthropological Writing. 


\section{Introdução}

ב m um trabalho clássico na área de antropologia do desenvolvimento, Akhil Gupta (1998) buscou enfrentar a questão de como a teoria pós-colonial poderia contribuir para identificar, descrever e analisar as conjunturas criadas por aparatos de desenvolvimento que a partir da segunda metade do século XX passaram a marcar as vidas e experiências de pessoas que eram alvo de grandes projetos desenvolvimentistas. Uma tal exploração etnográfica significava, no seu caso, tomar atenção a como compreensões locais da agricultura em Alipur, no norte da Índia, foram profundamente moldadas por discursos de desenvolvimento que circulavam global e nacionalmente. Assim, Gupta explora como, entre os agricultores, lógicas contraditórias e discursos incomensuráveis eram entremeados para explicar as suas decisões em torno de práticas agrícolas - que o autor chamou de "agronomia humoral" -, incluindo aí teorias científicas, discursos presentes em programas estatais de desenvolvimento agrícola, políticas de classe, casta e gênero. Para o autor, a teoria pós-colonial ofereceria um enquadramento analítico que possibilitaria descrever como discursos e práticas locais e globais estão imbricados, permitindo assim:

[...] um tipo diferente de compreensão das práticas e discursos indígenas, que não busca determinar se algo é autêntico, original ou não contaminado, mas que aceita o hibridismo cultural como um ponto de partida em projetos políticos que procuram empoderar grupos marginais, pobres, subalternos. (Gupta, 1998, p. 20) ${ }^{1}$

No Brasil, tal abordagem encontrou ressonância, sobretudo, na sua negação, em especial a partir da noção bastante disseminada de 
indigenização da modernidade de Marshall Sahlins (1997). Rechaçando uma ideia corrente que, segundo ele, identificava culturas como " $[\ldots]$ pastiches de costumes locais e fluxos transnacionais, sem qualquer ordem ou estrutura próprias [...]" (Sahlins, 1997, p. 50-51), Sahlins argumenta que a crescente integração global teria provocado a reafirmação e fortalecimento de culturas locais, o que renovava a tarefa dos antropólogos em etnografar a maneira como estas significavam o capitalismo em seus próprios termos. Entre os trabalhos criticados por Sahlins estava aquele de Gupta e Ferguson (1992) que problematizava a relação entre espaço e cultura subjacente a teorias antropológicas. ${ }^{2}$ Se o mundo pós-colonial era formado por "[...] espaços interdependentes e interconectados culturalmente, socialmente, economicamente $[\ldots]^{\prime \prime}$ (Gupta; Ferguson, 1992, p. 14), diziam os autores, então os antropólogos não deveriam tomar as diferenças como pré-existentes em espaços cultural e geograficamente delimitados, mas sim explorar a construção das diferenças a partir de um processo histórico de relações entre pessoas, práticas, discursos dos mais diversos.

Apesar de muito interessante, o debate em torno de quais palavras-chave funcionariam melhor para a análise antropológica, se indigeneidade e tradição ou zonas fronteiriças e hibridismo, não é objetivo deste artigo reavivá-lo. Pois fazê-lo implicaria adotar um procedimento comum a textos antropológicos: colocar lado a lado as teorias de cultura implícitas em cada uma das abordagens para tomar uma posição, estabilizando assim uma perspectiva particular. A menção ao debate importa aqui, ao contrário, pelo movimento analítico que possibilita, ao fazer com que uma linha em grande medida preterida na antropologia brasileira - a teoria pós-colonial - apareça mais uma vez. Como ensina Marilyn Strathern (2011), ao discorrer sobre o raciocínio antropológico e a maneira como compomos nossos textos, abrir pontos de bifurcação ao fazer ver distinções conceituais e mantê-las explícitas permite que a análise vá tomando rotas diferentes, ao mesmo tempo em que evita que os termos se dissipem: "Pois uma distinção entre termos também os mantém em relação: eles ainda podem ser encontrados na companhia um do outro, o que se pode repetir, a qualquer momento, mais tarde" (Strathern, 2011, p. 90). 
Neste artigo buscarei, à luz de meu trabalho de campo com educadores populares em Recife e Olinda que participavam de organizações locais financiadas internacionalmente, levar adiante o desafio colocado por Gupta sobre como descrever processos de transformação das pessoas sobre as quais incide o aparato do desenvolvimento. ${ }^{3}$ A estratégia argumentativa aqui adotada não se valerá de uma mera tomada de posição da perspectiva pós-colonial para prospectar uma possível "pós-colonialidade" no Brasil contemporâneo. Ao contrário, a estratégia será a de operar uma série de movimentos de bifurcação analítica provocados pelo encontro entre meu material de campo e conceitos da teoria pós-colonial, para assim explorar o que emerge quando se coloca teóricos na companhia de educadores populares.

Na primeira parte, aproximarei a noção de "tempo de emaranhamento" de Achille Mbembe (2001) e "inscrições intersticiais da diferença" de Homi Bhabha (2003) da fala de educadores populares formados dentro de organizações não governamentais que trabalhavam com meninos e meninas de rua em Recife e Olinda nas décadas de 1990 e 2000. O ponto de partida será a fala de Jucélia, 36 anos, moradora desde os 7 anos de idade no bairro de Santo Amaro, no norte de Recife, e durante 19 anos, educadora de pintura de uma das organizações atuantes no Movimento Nacional dos Meninos e Meninas de Rua (MNMMR), o Galpão dos Meninos e Meninas de Santo Amaro:

( 1:10) Eu entrei no Galpão, eu tinha 17 anos, eu acho... foi assim que minha mãe faleceu, né... aí eu tive uma oportunidade de entrar no Galpão aonde eu me descobri como pessoa, né... assim, praticamente eu entrei leiga no assunto, o que era criança, o que era adolescente, a problemática da comunidade eu não entendia muito... aí depois assim... eu acho que é porque assim... eu não tinha despertado pro social. (Jucélia, Galpão dos Meninos e Meninas de Santo Amaro, 2006) ${ }^{4}$

Posicionar Jucélia e outros educadores lado a lado com Mbembe e Bhabha tem como efeito fazer emergir um argumento particular. Organizações alvo de cooperação internacional como o Galpão e, portanto, parte do chamado aparato mundial do desenvolvimento, 
incitavam os educadores populares a falar de si a partir das noções de raça, gênero, sexualidade e cultura. O processo iterativo de narrar suas vidas provocava o que Jucélia chama de despertar para o social, muitas vezes também referido como conscientização. Desse modo, as instituições tornavam-se espaços de enunciação em que educadores intercruzavam experiências passadas, presentes e futuras e incorporavam certas inscrições da diferença como dimensão significativa na sua vivência: tornava-se assim mulher, negro, homossexual, artista, educador.

O primeiro movimento do texto, portanto, permite explorar no contexto brasileiro uma das constatações etnográficas de Gupta (1998, p. ix) no seu campo na Índia: “ [...] quem as pessoas pensam que são, como elas se tornam aquilo, e o que elas podem fazer para alterar suas vidas foi profundamente afetado pelas instituições, ideologias e práticas do desenvolvimento".

Pois, como argumentei em outra ocasião, a atuação das organizações que trabalhavam com crianças e adolescentes em Recife e Olinda não podia ser pensada de forma descolada das relações institucionais nacionais e internacionais que fortaleciam o movimento de base dos educadores populares envolvidos com o MNMMR (Morawska Vianna, 2015). Treinamentos conjuntos garantiam a circulação de categorias e práticas que eram estabilizadas institucionalmente (Morawska Vianna, 2014). Narrar histórias de vida, por exemplo, era um dos métodos disseminados entre educadores populares que, como lembra Jucélia, provocava um potente efeito de transformação.

Para além desse argumento, o primeiro movimento faz também ver a proeminência do tempo nos conceitos pós-coloniais aqui mencionados. Isso abre outro ponto de bifurcação analítica que tem como vetor a discussão sobre tempo e mudança em dois modelos sociais discordantes, de Homi Bhabha e Pierre Bourdieu. Quais as implicações de se pensar as histórias de vida dos educadores a partir da noção de inscrições intersticiais da diferença ou como expressões simbólicas determinadas por uma experiência de classe? Argumenta-se que no primeiro modelo a sucessão do tempo instaura uma margem de instabilidade no espaço de enunciação, por isso a importância de atentar para a iterabilidade das enunciações na análise; no segundo, a sucessão do tempo se revela 
pelo deslocamento no espaço social, isto é, na estrutura de relações de classe, daí o lugar privilegiado das trajetórias de vida em análises por ele inspiradas.

Também este debate abre um último ponto de bifurcação, dessa vez que nos faz repetir aquilo que apareceu apenas no começo: um dos lugares em que a teoria pós-colonial aflorou na antropologia brasileira e as implicações do uso de trajetórias de vida para abordar a interseccionalidade entre raça, gênero, sexualidade, classe. Os educadores voltam para nos ensinar algo sobre os procedimentos que adotamos para fazer nossas análises, ao eliciar a diferença entre o que chamam de histórias de vida e o que os antropólogos tomam por trajetórias de vida. O que está em questão é como manter a proeminência das noções de nossos interlocutores nas análises antropológicas, ao mantê-las explicitamente diferenciadas da teoria, como corpos que permanecem externos uns aos outros, e cujo encontro provoca novas aberturas.

Antes de prosseguir, cabe um comentário sobre o material de campo aqui apresentado. Todas as falas dos meus interlocutores de pesquisa foram gravadas em junho e julho de 2006, no momento em que eu encerrava meu trabalho de campo, após meses de convívio, conversas e atividades conjuntas sem a mediação de um gravador. Meu método de pesquisa era a observação participante, não entrevistas. Já com vínculo com os educadores, após centenas de páginas de diário de campo escritas e prestes a partir, sugeri aos educadores uma conversa gravada, em que eles me contassem sobre suas vidas, uma prática que havia visto acontecer recorrentemente ao longo dos meses ali passados. Os educadores são pessoas públicas em suas comunidades, e o que compartilharam comigo era também público: as transformações que a experiência de ser um educador operou em seus corpos e sua visão de futuro. Mantenho, por esse motivo, seus nomes originais.

\section{Histórias de Vida: aproximações com teóricos pós-coloniais}

Todos os educadores que conheci em Recife e Olinda traziam a lembrança do trabalho iniciado ainda na infância. Esse é o caso da já mencionada Jucélia: 
( $1: 44)$ A infância da gente foi o seguinte, a gente trabalhava em casa de família... quando a nossa mãe morreu, a gente teve... assim... que assumir serviços domésticos como lavagem de roupa, que era roupa de ganho, né? Eu e [minha irmã] Simone, a gente teve que criar nossos irmãos... (3:02) Minha mãe quando morreu eu ia fazer 16 anos... (8:22) Eu sei que... tudo isso que a gente passou, né... nós criamos uma proteção, que a gente foi criado praticamente sem pai e sem mãe... uma coisa muito boa que nossos pais passaram pra gente foi o seguinte, um princípio que você tem de uma educação, você tá entendendo, mas em questão de sonho, tanto fez tanto faz... pra sonhar... a gente não tinha sonho, nós viemos sonhar agora... eles botavam muito assim essa questão do trabalho. Trabalho, trabalho, a gente trabalhava muito... foi quando eles morreram que a gente começou a sonhar... ter uma casa melhor, ter um trabalho melhor, que aquilo de você tá vivendo em casa de família não dava. (9:45) Antes da gente entrar no Galpão a gente vivia de catar sururu, tinha 7 lavagens de roupa, era uma por dia, aí dividia as tarefas... (11:51) A gente catava roupa do lixo, várias vezes o patrão da gente pegava a gente catando roupa do lixo... mas sempre a gente vivendo em questão de resto... aí ficava sempre naquela questão assim, sempre de resto, sobrou uma janta... manda... Sobrou uns ossos de umas galinhas, que eles trabalhavam num restaurante... aí dava aqueles ossos pra gente fazer uma coisa... sempre de resto, de resto... e no Galpão a gente começou a despertar o nosso potencial... não é ter vergonha desse passado... porque eu tenho orgulho, porque foi de lá que eu me fortaleci como pessoa... foi de lá que a gente pôde restaurar os sonhos de Ruth [irmã criada como filha]... porque Ruth poderia ser o quê? Ser uma traficante ou uma prostituta, porque ela é uma menina bonita... (Jucélia, Galpão dos Meninos e Meninas de Santo Amaro, 2006)

Como educadora no Galpão, Jucélia incitava as crianças a refletirem sobre suas vidas ao narrá-las, prática que os próprios educadores eram estimulados a fazer pela agência britânica que os financiava, a Catholic Agency for Overseas Development (CAFOD), que se valia de histórias de vida de seus beneficiários para inspirar seus doadores nas paróquias da Inglaterra e País de Gales (Morawska Vianna, 2014). Na sua fala, há a construção narrativa do passado e da infância como sendo um 
mundo de trabalho, trabalho, trabalho, a gente trabalhava muito... a gente vivia de catar sururu, tinha 7 lavagens de roupa, era uma por dia, de sacrifício, acordava em cima daqueles mariscos... virava a noite... tinha a roupa pra eu pegar de manhã, eu começava às 5, de precariedade, sempre a gente vivendo em questão de resto, lixo, sobra, sempre de resto. Para Jucélia, no Galpão seu potencial havia sido despertado. Ele estava presente desde sempre, ainda que adormecido. Seu sonho havia sido restaurado. Ele também já estava lá desde sempre, mas comprometido. E a partir da sua experiência como educadora e sua prática narrativa cotidiana criava-se um vetor de transformação no presente.

É tentador aproximar a fala de Jucélia dos escritos do autor camaronês Achille Mbembe, em especial o que ele chama de tempo de emaranhamento. Na narrativa acima, o passado, presente e futuro se entrelaçam, produzindo o que Jucélia concebe como uma experiência de transformação e Mbembe como um tempo emergente:

Como uma era, a pós-colônia comporta múltiplas durées feitas de descontinuidades, reversões, inércias e oscilações que se revestem uns aos outros, interpenetram uns aos outros e envolvem uns aos outros: um emaranhamento. (Mbembe, 2001, p. 14)

Ainda que vivida de modo particular e local, essa multiplicidade de tempos e trajetórias não pode ser concebida senão dentro de um mundo globalizado. No caso de Jucélia, isso significava que as dicotomias subdesenvolvido/desenvolvido, analfabeto/alfabetizado, pobre/rico, tão comuns às narrativas do "mundo do desenvolvimento" que envolviam a financiadora CAFOD e o próprio Galpão por meio dos canais institucionais que sua relação de parceria inaugurava, também se faziam de alguma forma presentes na sua fala, ainda que não a contivessem completamente: não é ter vergonha desse passado... porque eu tenho orgulho, porque foi de lá que eu me fortaleci como pessoa.

Assim como o antes e depois para Jucélia, o foco de Mbembe (2001, p. 16) é na experiência do tempo tal como vivido, “[...] o momento em que diferentes formas de ausência se tornam misturadas: ausência das presenças que não são mais e sobre as quais se lembra (passado) e ausência de outras que estão por vir e são antecipadas (futuro)". 
A morte da mãe, ter se criado sem pai e sem mãe, viver de catar sururu e lavar roupa, catar roupa no lixo, viver de resto: o passado que a fortalece como pessoa, que desperta o sonho presente e que instaura mais uma ausência, dessa vez o que não se é: sua irmã poderia ser traficante ou prostituta. É desse emaranhamento, inscrito em Jucélia e agenciado por sua fala, que se abrem possibilidades no tempo emergente.

Também José Luiz, 24 anos, jovem educador do Galpão, nascido e criado em Santo Amaro - até o nascimento foi dentro da comunidade - lembrava ao contar sua história de vida a vivência do trabalho na infância, trazendo para o presente a projeção passada de um futuro sem muitas possibilidades:

(8:42) Teve um tempo, assim, quando eu era menor né, antes de praticar capoeira, eu sempre fazia aquela coisa de flanelinha, que chama, né? Guardar carro... lá próximo ao hospital da restauração... Dava [dinheiro], era até bom... mas eu já tenho uma visão mais futura, porque eu sabia que tando ali, de flanelinha, meu futuro ia ser aquilo e só aquilo mesmo... e também foi influência da capoeira, né... Tem muitas pessoas que falam que capoeira é só malandro, e tudo o mais, mas eu vejo que mudou totalmente a minha vida com relação a essa visão. (José Luiz, Galpão dos Meninos e Meninas de Santo Amaro, 2006).

A capoeira muda a sua visão de futuro, e ao mencionar tantas vezes a palavra visão enxerguei finalmente a sua camiseta preta com dizeres brancos "100\% negro". Perguntei se vesti-la tinha a ver com a experiência da capoeira.

(9:49) Tem... Essa coisa de você conhecer a cultura, tanto da capoeira e também dos negros, tanto conteúdo, tanto sofrimento, você estudar... lá tinha muito esse trabalho de tá propondo um pouquinho da história da capoeira... aí você se envolvia não só na capoeira, mas em todo um conjunto cultural... Eu sempre valorizo essa coisa do negro e das pessoas que se sentem negras mesmo sendo brancas... porque tem muitas pessoas... brancas mesmo... mas que acho que é mais negro do que aquele cara que ta lá... ó, eu sou negro, mas pô não sou tão preto assim não... discriminação mesmo... ele não tem essa visão. 
Tendo se iniciado com 14, 15 anos, mas o desejo desde bem pequeno, a capoeira operou uma transformação radical em José Luiz: mudou totalmente a minha vida em relação a essa visão. Como numa espécie de mudança de enquadramento, a capoeira lhe proporcionou uma nova visão a partir da qual passou a se guiar. Surgiu para ele, no seu dia a dia, a referência da raça. A partir dessa experiência, e como forma de difundir sua visão, José Luiz se tornou um instrutor voluntário de capoeira. E foi como tal que ingressou no Galpão com 20 anos de idade.

Entre os educadores que conheci, além de José Luiz, também Daniel, educador de percussão do Galpão, tinha essa visão: raça era categoria vivenciada politicamente. Ao contrário do primeiro, cuja iniciação se deu por meio da capoeira, o segundo incorporou a categoria a partir do seu contato com terreiros de candomblé. Desde pequeno eu vou. E ao falar sobre seu trabalho como educador, menciona a sua experiência no candomblé e o preconceito por parte da comunidade, deixando claro que o que certos cientistas sociais considerariam diferentes "campos sociais" - dos terreiros, das ONGs, dos grupos de capoeira - cruzamse constantemente:

Maracatu, frevo, caboclinho, coco, afoxé... várias diversidades de ritmos e que hoje a comunidade já percebe que não é a coisa que eles pensavam... ah, vou botar meu filho na macumba pra fazer coisas maus... não, vou botar meu filho pra ele mudar... ritmos que a gente toca aqui... (Daniel, Galpão dos Meninos e Meninas de Santo Amaro, 2006)

No dia em que passamos horas conversando, quando Daniel paciente e didaticamente me explicou toda a simbologia religiosa em torno dos toques nos instrumentos e dos rituais que ele me convidava a visitar, via os frutos de seu esforço em iterar e disseminar a sua visão: Vander, um jovem de 18 anos morador de Santo Amaro, ex-educando do Galpão, era treinado por Daniel para ser tanto um futuro educador quanto um iniciado no candomblé.

Se para Vander, Daniel e José Luiz a experiência transformadora foi a da negritude, para Erika a transformação se deu por meio da ideia de gênero, pensada a partir de narrativas sobre a vivência de si como mulher. Jovem educadora de 31 anos, moradora desde os 7 anos 
do Alto Sol Nascente, bairro periférico de Olinda, também começou a trabalhar cedo, aos 12 anos, na barraca do tio. ${ }^{5}$ Estudava e trabalhava, até que um dia na escola se interessou em participar de um grupo de discussões entre adolescentes, promovido por uma ONG chamada Coletivo Mulher Vida:

(12:20) O Coletivo desenvolvia um trabalho no Sol Nascente sobre prevenção à violência doméstica e sexual. Comecei a participar de um grupo, era um grupo só de meninas, a gente se sentia mais à vontade porque era só meninas... abordavam vários temas, sexualidade, drogas. (12:55) O Coletivo Mulher Vida desenvolvia trabalho sobre violência doméstica e sexual dentro dos bairros... eram vários bairros de Olinda, se não me engano eram 13 bairros, Alto Sol Nascente, Alto da Bondade, Rio Doce, Ilha do Rato, tinha vários pontos onde desenvolvia o trabalho. (24:00) O Coletivo só atendia mulheres, então meninos, forinha [risos], era o clube da Luluzinha... (Érika, Galpão dos Meninos e Meninas de Santo Amaro, 2006)

Foi nessa ONG, que atuava de forma descentralizada, que Erika foi menina no grupo de adolescentes, mulher no grupo de mulheres (funcionava na casa da minha tia) e posteriormente educadora (trabalhei lá ainda durante dois anos). A vivência de Erika no Coletivo, assim como ocorrera com Daniel, Vander e José Luiz em terreiros, grupos de capoeira e no Galpão, teve profundas implicações no modo de enxergar seu próprio corpo:

(20:50) Na época eu via como um grupo que eu podia falar, era um espaço que eu tinha, chegava lá podia falar minhas coisas, coisas que... eu tinha muito a minha mãe como amiga, mas tem coisas que não se diz à mãe... de jeito nenhum [risos] ...então lá nesse espaço, além de eu falar, eu escutava o que as outras meninas também... então, poxa, não sou eu sozinha, tem um monte de gente também, então isso me fortalecia... me fortaleceu muito nesse aspecto... então mudei várias coisas, até jeito de pentear cabelo, que era todo preso, só olhava pra baixo, nem olhava no rosto das pessoas, passei a olhar... várias coisas foram mudando a partir dessa coisa de vivência em grupo, porque isso me fortaleceu e acho que me fortalece muito... não é à toa que eu gosto desse trabalho, 
principalmente com adolescente, eu me sinto muito bem trabalhando em grupo. (Érika, Galpão dos Meninos e Meninas de Santo Amaro, 2006)

Clébisom, por sua vez, educador de arte de 31 anos do Sobe e Desce, teve na sexualidade uma de suas principais dimensões transformadoras, em um sentido similar ao explorado aqui para José Luiz, Daniel, Vander e Erika. Originalmente de Santo Amaro (cresci na comunidade de Santo Amaro, bairro carente mesmo... terra maldita, terra de morte, de droga, de cachaça), onde ficava preso dentro de casa para evitar a violência do bairro, mudou-se para o Amaro Branco, em Olinda (minha terra sagrada), onde se viu solto:

(14:00) Eu ficava assim solto, era montanhas, barreiras... ali no Bonsucesso, na ligação com Amaro Branco, tem umas partes ainda que tão muito mato, muito floresta, muito terra... naquela época não havia nem casa... aquela estrada do Bonsucesso ali era barro. (Clébisom, Grupo Sobe e Desce de Olinda, 2006)

Nesse cenário bucólico, inicia-se a sua transformação:

(16:20) Quando chegou minha adolescência começou a aflorar, né, meus desejos... e meus desejos não foi o natural que eles [meus pais] queriam... [risos] Eu comecei a sentir gosto por pessoas do mesmo sexo que o meu... com 14 anos... me lembro que tava na sala e o menino me mostrou o negócio... na escola... chegou um boy lá que era da minha idade e ficou à vontade... e aí, tu gosta? Fiquei assim olhando, nunca tinha visto as partes íntimas de ninguém...ele me mostrou e fiquei com aquilo na cabeça... aí depois outros garotos começaram a perceber que eu também gostava, começaram a ter relação comigo... a professora viu, começou a dizer, oi, isso não é coisa de homem... você tá se tornando afeminado... começou a dizer à minha mãe... meu pai ficou em conflito, ele disse não acredito que você vai ser bicha... comecei também a esconder, não queriam entender... meu pai disse olhe, se eu vê você com isso vou lhe matar, viu? Pegou uma peixeira... Vou lhe mataaaar, você é viado, é? Tá ficando viado, é? [risos] A família de minha mãe morava toda lá... aí comecei a me envolver com eles... Clébisom, bóra pro sitio pegar frutas? ...Ia com meus primos pra dentro 
do mato, chegava lá, tinha outros meninos... Começava aquela surubada dentro do sítio... aquela coisa louca, comecei a me apegar com a turma... comecei a gostar, foi um momento muito bom da minha vida... (Clébisom, Grupo Sobe e Desce de Olinda, 2006)

A liberdade e o barro de Amaro Branco lhe deram duas descobertas que pareciam se mesclar: sua sexualidade e a paixão pela cerâmica.

(19:45) ...comecei a andar pelos caminhos lá do Amaro Branco, pelos sítios, pelas barreiras, e encontrei o quê? Minha segunda paixão, a cerâmica. Eu encontro uma barreira e começo a pegar o barro... oxi, esse barro aqui é mole... nunca vi isso... parece massa de modelar que meu pai me dá pra fazer presépio... (20:30) - comecei a pegar barro, nos campos, nas barreiras... chegava com o saco cheio de barro... chegava no meu quarto e ficava lá... começava a fazer... fazia tudo o que eu via, tuuudo o que eu via na comunidade eu fazia... fazia homem bebendo, fazia mulé tomando conta do filho pra amamentar, fazia o homem em cima da mulé... porque era um beco, né? E tinha um quartinho lá que tava alugado a uma mulher... porta cheia de brecha... vi a mulé em cima do homem transando... eu digo, misericórdia... fiquei com aquilo na cabeça... eu, oxi, vou fazer a mulher transando com o homem... botava o pauzinho do homem, botava o negocinho na mulher... fazia os bonecos tudo enrolado. (00:00 II)...voltei pra Santo Amaro, já ia fazer 15 anos, já era assumidíssimo na minha sexualidade... só que pra mim, sair de Olinda foi terrível porque eu deixei pessoas lá que eu gostava, ficou na saudade, aqueles meninos, aquelas imagens, aquelas cenas, aquelas histórias... (Clébisom, Grupo Sobe e Desce de Olinda, 2006)

É apenas mais tarde, em uma organização que trabalhava com crianças, que a dimensão da arte se sobrepõe à da sexualidade, antes misturadas nas suas experiências de infância: tantas outras coisas mais importantes pra eu me preocupar. Foi na Casa das Crianças de Olinda, uma das instituições precursoras na área de educação popular na década de 1980, da qual participaram como educandos muitos dos educadores mais antigos, que Clébisom aprendeu cerâmica, dança, teatro de bonecos (mamulengos), encadernação, estamparia, pintura em tela, em tecido, 
comecei a me envolver com várias culturas. Pode-se supor que, se ao invés de uma organização voltada às crianças, Clébisom tivesse se envolvido com outra focada nos direitos LGBTT, teria sido a dimensão da sexualidade aquela a se politizar; mas lá era a categoria cultura a predominante.

O mesmo aconteceu com Erivan, 28 anos, educador do Grupo Comunidade Assumindo suas Crianças, também financiado pela CAFOD e parte da rede de organizações em torno do Conselho de Direitos da Criança e do Adolescente de Olinda. Erivan havia sido atendido como menino na época da formação do grupo, quando este ainda nem prédio-sede tinha:

(9:50) A ligação com coisas artísticas veio com a ligação com o grupo, desde os 8 anos de idade... participei com a primeira educadora, Socorro, no terreno do seu Deda. (Erivan, Grupo Comunidade Assumindo suas Crianças, 2006)

Apesar de seu pai ser um conhecido tocador de coco em Peixinhos, foi apenas no Grupo Comunidade que desenvolveu o gosto pela arte. Foi lá que aprendeu a mexer com gesso, a pintar, a costurar, a dançar e a serigrafar:

(10:25) Tudo o que tinha no grupo, eu tentava participar, participei da dança, só percussão que eu não aprendi a tocar, só abê e atabaque, o resto não... eu participava da oficina de cultura com Dona Zuleide. (Erivan, Grupo Comunidade Assumindo suas Crianças, 2006)

Era Dona Zuleide que desde o início tocava a oficina de cultura, ensinando afoxé, maculelê, maracatu, frevo e, principalmente, contando as histórias do bairro. ${ }^{6}$ Se raça, gênero e sexualidade se mostravam na vida de uns como vetor de transformação, para Zuleide era o fato de levar, manter, resgatar, reinventar a cultura popular por meio do Grupo Comunidade. É interessante notar que quando Erivan comenta sobre a expressão cultural no bairro, o que enfatiza é o espaço da fala na prática desses grupos:

(35:30) Aumentou bastante... a gente trabalhando a parte cultural, a gente vê que os adolescentes desenvolveram bastante, eles sabem reclamar, sabem reivindicar, eles 
sabem dizer quando tá errado, isso tudo dentro do trabalho cultural... eles mesmos cobram bastante, pedem desculpa quando tão errados, isso tudo englobado dentro do trabalho cultural. (Erivan, Grupo Comunidade Assumindo suas Crianças, 2006)

A experiência da fala é extremamente importante na prática não apenas desses três grupos com seus meninos, como também na trajetória de seus educadores. Todas essas transformações eram reforçadas e se faziam visíveis a cada repetição da narrativa em espaços institucionais. José Luiz na capoeira do Galpão, Erika no Coletivo, Daniel, Clébisom e Erivan no núcleo de base do MNMMR, como lembra Erivan:

(12:50) Eu sempre participei do núcleo de base, aí quando tinha capacitações, conferência, tudinho, aí eles mandavam a gente que tinha mais desenvoltura, que sabia mais dialogar, tudinho, aí eu acho que é graças a isso que eu tenho essa mente... elas sempre: vai Van, tu que é mais desinibido, tu consegue mais falar, que entende as coisas rápido, acho que foi graças a isso que eu tenho essa formação, de desde pequeno estar debatendo, levando minhas ideias, propostas... isso ajudou bastante. (Erivan, Grupo Comunidade Assumindo suas Crianças, 2006)

Também Robson, 21 anos, educando desde pequeno de outra organização financiada pela CAFOD, o Grupo Sobe e Desce de Olinda, fazia as atividades com os educadores na rua enquanto guardava carros no Varadouro (Olinda), e passou a fazer parte do núcleo de base que existia no Sobe e Desce:

(12:40) O Movimento [Nacional dos Meninos e Meninas de Rua] pra mim... foi uma escola da vida... pra mim particularmente foi uma escola. Do Grupo Sobe e Desce saí pro núcleo de base... os meninos mais organizados, mais interessados... na época que eu participei tinha 23 núcleos de base... comecei a participar com uns 12 anos de idade... num dos núcleos no Sobe e Desce... discussão sobre direitos e deveres, sobre o Estatuto da Criança e do Adolescente, sobre o que é que tá acontecendo no país, o que é que tá acontecendo na sua comunidade, no seu bairro... tipo uma roda de dialogo, aí o Movimento organizava encontro entre os núcleos de base... (17:10) ...me ensinou tanta coisa... sua timidez, de tá em grupo 
falando... expressando... porque tem muita pessoa que é tímida... a hora de você falar, a hora de saber escutar... Tem muitas pessoas que moram em comunidade, não sabem o que acontece no país... era um espaço de trazer... ó, tá acontecendo isso, aquilo, aquilo outro. (Róbson, Grupo Sobe e Desce de Olinda, 2006)

A isso que o Movimento ensinou para Robson os educadores chamavam conscientizar, uma noção influenciada pela pedagogia do oprimido de Paulo Freire que, ainda que raramente lida, encontrava-se disseminada nos encontros, treinamentos, conferências promovidos pelas instituições voltadas à defesa dos direitos das crianças e adolescentes e era praticada na lida diária com os meninos.

Ao aproximar todas essas falas de mais um importante autor para a teoria pós-colonial, Homi Bhabha, o aspecto que se realça é que todas essas instituições fomentavam espaços em que educadores e educandos eram incitados a enunciar narrativas de vida a partir das noções de raça, gênero, sexualidade e cultura, possibilitando o que o autor chama de inscrições intersticiais da diferença (Bhabha, 2003). Especialista em estudos literários pós-coloniais, o autor indiano parte da noção de espaço de fronteira (o terceiro espaço) para abordar o que denomina local da cultura. Tendo por base o princípio de rasura de Derrida, o terceiro espaço apontaria para as iterações enunciativas que hibridizam o discurso colonial. A noção de rasura tem como principal efeito considerar que todo e qualquer diálogo, por exemplo, implica não na discussão de ideias constituídas previamente que se enfrentam, mas em um processo de constituição dos argumentos ao longo do diálogo, a partir da palavra primeira, que é então rasurada para ser contraposta, e daí por diante seguindo num processo de contínua rasura. Aplicada às interações simbólicas, conclui-se que não há culturas totais prévias que se encontram e dialogam, mas sempre culturas híbridas, já rasuradas a partir de encontros-rasuras prévias. É por isso que no local da cultura há a operação de um processo de hibridização contínuo, não como resultado de elementos simbólicos e culturais pré-constituídos que criam um "outro" com elementos prévios de um e outro, mas que abrem espaço para a experiência que é rasurada, "nem uma nem outra", ambígua, nova, híbrida. Vivências híbridas são inauguradas a partir da 
rasura do outro, nesse espaço de fronteira, de tradução, possibilitando o que Bhabha chama de resistência em contextos coloniais, bastante distinta da já mencionada resistência das culturas locais tal como descrita por Sahlins.

Deslocando Bhabha, portanto, para junto dos educadores populares, poderia se dizer que eles eram incitados a práticas enunciativas dentro de instituições que lhes abriam novas possibilidades, afastando-os das categorias de subdesenvolvido ou pobre que circulavam pelas organizações financiadoras como CAFOD, que se valia de suas histórias de vida para publicizar o trabalho que fazia com os parceiros ao redor do mundo e ressaltar a mudança do que lhe parecia relevante: a superação de dificuldades financeiras, a manutenção de um senso de comunidade, a resiliência frente a desastres naturais ou injustiças sociais (Morawska Vianna, 2014). O que todos os educadores narravam era de fato uma transformação, ainda que bastante diferente daquela que se divulgava entre doadores em paróquias na Inglaterra e País de Gales. Por meio da familiarização com noções de raça, sexualidade, gênero, cultura, os educadores as tomavam para si como referências identitárias, em um processo que denominavam conscientização. Tornavam-se, assim, mulheres, negros, homossexuais, artistas, educadores. Essas transformações constituíam um efeito inadvertido, colateral, daquilo que essas parcerias fomentavam, e que Ferguson (1994) descreveu primorosamente como a constituição de uma máquina antipolítica que institui e expande o exercício do poder estatal burocrático. Neste caso, que instituiu e expandiu formas institucionais (organizações não governamentais, contratos de parceria, gerenciamento de recursos) em torno da prática de educação popular nas décadas de 1990 e 2000 em Recife e Olinda.

É importante notar que nem todas as instâncias de enunciação citadas pelos educadores faziam parte de projetos de desenvolvimento financiados internacionalmente, ou sequer da mesma área de atuação. Para além das organizações de educação popular financiadas pela CAFOD - Galpão, Grupo Comunidade, Sobe e Desce, Movimento Nacional dos Meninos e Meninas de Rua -, Érika também mencionou uma organização feminista, o Coletivo Mulher Vida, José Luiz fez referência a 
um grupo de capoeira e Daniel e Vander aos terreiros onde se iniciaram. Foi, contudo, como educadores populares que a prática de narrar suas histórias de vida se tornou um método que articulava todas as experiências passadas, presentes e futuras a partir de categorias que mudavam a sua visão, e assim, fomentavam o que denominavam conscientização. Em outras palavras, quanto mais se proliferavam formas institucionais em torno da educação popular, mais se disseminava um gênero enunciativo muito particular - as histórias de vida -, cujos efeitos eram visíveis no próprio corpo dos educadores: a forma como penteavam seus cabelos, aquilo que exibiam orgulhosamente em suas camisetas, os termos que usavam, a maneira como se concebiam a si e ao mundo.

Se o primeiro movimento deste texto faz aparecer o tempo emergente aberto pela prática enunciativa em instituições, também elicia uma particularidade no modelo dos autores mencionados. Para ambos é o tempo a dimensão analítica privilegiada para uma teoria social atenta àquilo que emerge: para Mbembe, trata-se do tempo vivido, tempo de emaranhamento, tempo emergente; para Bhabha, o que importa é aquilo que o momento presente possibilita por meio da iterabilidade da enunciação nesses espaços institucionais.

A constatação da proeminência do tempo nas falas dos educadores e nos escritos desses autores pós-coloniais abre outro ponto de bifurcação no argumento. Deixo agora para trás, e assim oblitero apenas por um momento, os educadores populares. Eles voltarão mais adiante ao longo do texto. Por ora, o que é colocado lado a lado nessa nova bifurcação é a maneira como tempo e mudança são pensados em modelos teóricos tão distintos quanto os de Homi Bhabha e Pierre Bourdieu. Com isso, emerge a pergunta: quais as implicações de se pensar as falas dos educadores populares a partir da noção de inscrições intersticiais da diferença ou, de outro modo, como expressões simbólicas determinadas por uma experiência de classe? 


\section{Tempo e Mudança: amarras de classe e a iterabilidade da enunciação}

Se todos os educadores que conheci em Recife e Olinda traziam a lembrança do trabalho iniciado ainda na infância, então um cientista social poderia inferir que todos viveram experiências fortemente determinadas pelo que Pierre Bourdieu (1983) chamaria de "condições objetivas", para ele entendidas como relações de estrutura de classe, especialmente no que diz respeito à dimensão do trabalho como prática iniciada ainda na infância:

[...] as interações simbólicas no interior de um grupo qualquer dependem não somente [...] da estrutura do grupo de interação no qual elas se realizam, mas também das estruturas sociais nas quais se encontram inseridos os agentes de interação (isto é, a estrutura das relações de classe) $[\ldots]$ o simples conhecimento do código não permite (aos agentes) senão imperfeitamente dominar as interações lingüísticas realmente efetuadas. [...] A recepção (e, sem dúvida, também a emissão) depende, pois, em grande parte da estrutura das relações entre as posições objetivas dos agentes em interação na estrutura social [...]. (Bourdieu, 1983, p. 52-3)

Para o autor, a recepção e a emissão dos elementos lingüísticos dependem da estrutura das relações sociais. Menos ênfase, portanto, é dada àquilo que Bhabha enfatiza: as possibilidades abertas pelos atos de enunciação a partir das narrativas cotidianas de sonhos, desejos, opiniões, imaginário. Pois para Bourdieu, a amnésia da gênese - a maneira pela qual a história é inscrita em nós pela dinâmica das estruturas que se reproduzem em e por meio de nós - também afeta as contingências da vida cotidiana transformadas em temas centrais nas conversas, nos cochichos, nos rumores, que então, ao assumir o espaço da enunciação, se objetificam e se constituem como real pré-constituído, as "condições objetivas de existência". Eis o sistema de disposições de Bourdieu: a interiorização da exterioridade (estruturas estruturantes que se tornam estruturas estruturadas, o habitus) e a exteriorização da interioridade (estruturas estruturadas postas em prática por meio do habitus). Para o autor, é a "estrutura de relações de classe" o dado objetivo que afeta o seu sistema de disposições (Bourdieu, 1983). 
A sobrevalorização da condição de classe é justamente a crítica que Bhabha (2003, p. 305-6, grifo nosso) faz a Fredric Jameson:

Sua concepção inovadora do sujeito político como uma agência espacial descentrada é cerceada por sua conviç̧ão de que o momento de verdadeiro reconhecimento da História - a garantia de sua objetividade material - reside na capacidade do conceito de classe de se tornar o espelho da produção social e da representação cultural. [...] É o valor investido na diferença visível de classe que não lhe permite constituir o momento presente como a insígnia de outras inscrições intersticiais da diferença cultural.

Como já dito, o aspecto mais significativo do modelo de Bhabha, a despeito do termo "local da cultura", é o momento presente que permite, por meio das enunciações, constituir outras inscrições da diferença cultural, incluindo aí a experiência de classe, mas destituindo-a do privilégio analítico de sobredeterminação do social. E se dentro das organizações em Recife e Olinda se estabilizavam as noções de raça, gênero, sexualidade, cultura ou até mesmo classe, eram elas que guiavam as histórias de vida dos educadores sobre violência, trabalho, abandono, sexo, dança, música, ritmos. Havia tantas outras coisas mais importantes pra eu me preocupar, como dizia Clébisom. Aquilo que se tornava importante era guiado pelas estabilizações das organizações de quais participavam e, assim, tornava-se negro, mulher, educador, artista.

Essa diferença de ênfase nas condições objetivas da estrutura social (amarras de classe) e o potencial de mudança aberto pela iterabilidade da enunciação foram abordados por Judith Butler (1997), em uma obra que busca explorar a performatividade dos atos de fala. A filósofa aponta que Bourdieu, apesar de oferecer um modelo promissor do mecanismo de incorporação não deliberada e não intencional das normas por meio de seu conceito de habitus, atém-se a uma visão conservadora ao negligenciar a força da performatividade desse mesmo habitus, que governaria a possibilidade da transformação, e não apenas a reprodução, das ditas estruturas sociais. A possibilidade de transformação é o que a autora chama de "operação política do performativo". A força da performatividade estaria na lógica da iterabilidade das enunciações, 
que não são asseguradas de antemão pelas posições sociais aos quais os agentes estariam mimeticamente relacionados (Butler, 1997, p. 145). Butler afirma que Bourdieu incorre em dois erros: o de pressupor que a formação dos sistemas de disposições é um processo completo, efetivado, acabado; e o de pressupor uma estrutura social externa, que determinaria em grande parte tais enunciações. Segundo ela, atos performativos não refletem meramente condições sociais, mas são fruto de interpelações que produzem um conjunto de efeitos de regulação e formação dos sujeitos, constituídos de forma contínua (nunca completa), discursiva e socialmente.

Para pensar a força do performativo, a autora se coloca num meio termo entre Bourdieu e Derrida, utilizando a leitura que ambos fazem da teoria do performativo do linguista J. L. Austin. De Derrida, Butler se apropria do conceito de "força da ruptura", que seria para o filósofo a característica estrutural de qualquer signo: o performativo teria como propriedade a descontextualização, sua quebra com contexto anterior e capacidade de assumir novos contextos. Butler aponta ressalvas ao caráter formalista da análise que Derrida faz da iterabilidade do signo grafemático, como uma característica inerente ao signo, mas independente das relações sociais. De Bourdieu, Butler incorpora o esquema da formação corpórea do sujeito social (habitus), mas crê que sua abordagem do performativo não dá conta do germe de mudança que a performatividade do habitus instaura. Entre um e outro, defende que o ideal é que houvesse o que chama de uma "[...] descrição da iterabilidade social da enunciação" (Butler, 1997, p. 150). Uma abordagem que enfatiza a iterabilidade social da enunciação, situada sempre no plano do contingente, implicaria uma atenção especial não ao padrão de certo campo social, mas à variação e novidade que emergiria da iteração enunciativa, o que como já abordamos, Mbembe explora em termos de tempo emergente e Bhabha de local da cultura.

O foco na sucessão do tempo leva à percepção da transformação que a iteração social da enunciação implica. No modelo de Bhabha, a narrativa se instaura sempre no tempo presente, e é a imprevisibilidade do espaço da enunciação que insere a instabilidade, germe de mudança. No modelo de Bourdieu, diferentemente, a enunciação depende das 
posições objetivas dos agentes na estrutura das relações de classe e, portanto, o que a sucessão do tempo revela é o deslocamento dos agentes no espaço social. Daí, como se verá adiante, o lugar da trajetória de vida em análises inspiradas pelo autor.

Esse segundo movimento do texto, ao tratar da sucessão do tempo e da mudança em modelos teóricos, nos fez chegar à noção de trajetória de vida, abrindo com isso um último ponto de bifurcação analítica, cujo vetor é o lugar das narrativas nas falas dos educadores e nas análises dos antropólogos. E, assim, emerge a pergunta: o que os educadores nos ensinam sobre a maneira como nós, analistas, contamos suas histórias? Isso nos leva de volta ao começo, a um dos lugares em que a teoria pós-colonial aflorou na antropologia brasileira, para assim eliciar as implicações de se tomar histórias de vida por trajetórias de vida.

\section{Histórias, Narrativas, Trajetórias de Vida}

De acordo com Adriana Piscitelli (2013), o impacto das teorias pós-coloniais na antropologia brasileira se evidenciou na produção antropológica feminista e sobre gênero a partir da metade da década de 2000, sobretudo na leitura crítica sobre as raízes coloniais que embasavam noções de cultura nacional e - o que nos interessa propriamente aqui - nas análises sobre processos de transnacionalização que realçavam identificações marcadas por gênero, raça, classe, sexualidade e nacionalidade. A inspiração vinha proeminentemente das noções de articulação e interseccionalidade que, como bem mostra Piscitelli (2008), passaram a ser amplamente utilizadas a despeito das diferenças no tratamento que recebiam de autoras como Kimberlé Crenshaw (1989, 1991), Anne McKlintock (1995), Brah e Phoenix (2004) e Avtar Brah (2006): ${ }^{7}$

A proposta de trabalho com essas categorias é oferecer ferramentas analíticas para apreender a articulação de múltiplas diferenças e desigualdades. É importante destacar que já não se trata da diferença sexual, nem da relação entre gênero e raça ou gênero e sexualidade, mas da diferença, em sentido amplo para dar cabida 
às interações entre possíveis diferenças presentes em contextos específicos. (Piscitelli, 2008, p. 266)

Laura Moutinho (2014) faz uma ampla revisão bibliográfica em torno da produção acadêmica brasileira influenciada por essa abordagem. Ao enfatizar não a particularidade das categorias de articulação e interseccionalidade dentro de diferentes modelos teóricos, mas o movimento analítico que elas promovem - o procedimento de articular e interseccionar o que denomina "marcadores sociais da diferença" -, a autora acaba por retroceder o marco inicial dessas produções no Brasil para antes mesmo da publicação original das obras de Crenshaw, Brah e McKlintock (1995, p. 215-216):

Vemos, portanto, um campo se configurando (mais ou menos a partir de fins da década de 70) sobre o entrecruzamento, a articulação, a intersecção entre marcadores sociais da diferença. Nem a análise de Adriana Piscitelli (2008), nem o levantamento realizado indicam alguma diferença teórica ou analítica relevante em se utilizar as expressões articulação ou intersecção dessas categorias. Os principais marcadores são gênero, sexualidade, raça (seguidos na articulação com classe, erotismo, geração, território e, muito mais recentemente, deficiência).

Não é o caso aqui de se fazer uma revisão bibliográfica dessa área de estudos, o que já foi realizado pelas autoras mencionadas. O que gostaria de ressaltar é o aspecto procedimental desses trabalhos, cuja proposta seria, segundo Schwarcz (2015, p. 8), “[...] a partir do trabalho de campo e da empiria [...] entender como se configuram hierarquias sociais complexas, sempre rearticuladas de modo tenso e contraditório, tendo por base marcadores como estes". Em geral, os autores que se pautam por essa agenda de pesquisa ora descrevem as classificações que emergem em contextos específicos, por exemplo, em Simões, França e Macedo (2010), ora fazem uso de trajetórias de vida, como é o caso de Moutinho et al. (2010).

A primeira estratégia se faz valer, segundo os autores mencionados, para analisar tanto as retóricas classificatórias que ordenam as interações quanto os deslocamentos nos sistemas classificatórios. Assim, em sua 
descrição das classificações realizadas por jovens em sua interação em bares do centro da cidade de São Paulo, os autores afirmam que

[...] os pertencimentos em termos de cor/raça, gênero e sexualidade, mesmo informando uma escala de prestígio e desigualdade, mostram-se também instáveis, contingentes e situacionais. (Simões; França; Macedo, 2010, p. 74)

A segunda estratégia - o uso de trajetórias de vida - justificase na análise de Moutinho et al. (2010, p. 173) para evidenciar reposicionamentos:

[...] a ansiedade desses jovens [sul-africanos] frente ao futuro que os espera traz igualmente dúvidas sobre os repertórios que eles adquiriram acerca das expectativas e performances de gênero, raça, sexualidade, herdados de suas famílias e culturas.

Em termos de temporalidade, ambas as estratégias permitem atentar para a mudança no campo: a instabilidade que o tempo presente abre (nas classificações) e a dúvida que a sucessão do tempo imprime (nas trajetórias). Mas também é interessante perceber o efeito dessas estratégias na antropologia, isto é, como o ato de narrar o que se vê, ouve e anota em campo abre e transforma os modelos teóricos. Categorias e narrativas dos interlocutores de pesquisa são articuladas e interseccionadas no texto como se fossem marcadores sociais da diferença; com esse movimento, provoca-se ainda outra articulação e intersecção, dessa vez entre o que se imagina como sendo "sistemas classificatórios" e uma "estrutura social". Nesse modelo, portanto, o deslocamento dos sistemas classificatórios também supõe um deslocamento no espaço social.

A relação entre trajetórias de vida e deslocamento no espaço social foi também questão enfrentada por Suely Kofes (2001) em etnografia que aborda a biografia de uma mulher goiana, Consuelo Caiado. Ao ponderar sobre as possíveis ferramentas que se colocavam para a sua análise, conclui que a adoção de uma noção bourdiana de trajetória de vida demandaria vincular um agente com outros agentes do campo social e, assim, situar os acontecimentos biográficos em deslocamentos no espaço social. Algo, contudo, ficaria de fora na análise: "Refiro-me 
às marcas que os sujeitos imprimem às suas interpretações e às suas existências, que não estão incorporadas na noção de agente social" (Kofes, 2001, p. 24). Dito de outro modo: o uso de trajetória de vida necessariamente vincularia as narrativas sobre Consuelo a certo modelo teórico que toma uma forma particular, desenhada a partir de noções como campo social, capital simbólico, estrutura de classes. Opera-se, assim, uma transformação: as narrativas do campo transmutam-se em trajetórias, deslocamentos dentro de um campo social. Não é de se surpreender que a solução a que a autora é levada, pelo que identifica como sendo uma "motivação êmica", é justamente "levar em conta a temporalidade e não apenas uma espacialidade social" (Kofes, 2001, p. 27). No caso de Consuelo Caiado, a autora argumenta que a sua reclusão a certa altura da vida parecia, a princípio, sugerir uma crise de relações sociais:

Embora este aspecto deva ser reconhecido nos momentos cruciais da experiência de Consuelo, a pesquisa mostroume um outro sentido. Sentido este marcado pela temporalidade. Ora, no plano estrutural, esta trajetória aponta para um congelamento da "série de posições sucessivamente ocupadas por um mesmo agente". Mas, em outro plano, esta trajetória agencia uma reversão da temporalidade. Digo agencia porque estou considerando que nos relatos sobre Consuelo há que levar-se em conta as narrativas tecidas por ela própria. A reclusão de Consuelo remete à sua tentativa de congelar uma temporalidade precisa. (Kofes, 2001, p. 27, grifos nossos)

No caso dos educadores populares em Recife e Olinda, levar em conta as narrativas tecidas por eles próprios implicava dar atenção ao que estas agenciam, isto é, os efeitos da prática de narrar as suas histórias de vida. Como argumentado anteriormente, os vetores que guiavam tais narrativas eram as noções de raça, gênero, sexualidade incitadas pelos próprios espaços institucionais em que os educadores se encontravam. Raça, gênero e sexualidade, portanto, apareciam em campo em um lugar muito preciso: nas instituições que incitavam a conscientização por meio de práticas narrativas. Os movimentos de bifurcação que a minha análise buscou operar provocaram também 
efeitos de transformação: no primeiro movimento, raça, gênero e sexualidade dos educadores se transmutaram em inscrições intersticiais da diferença; no segundo movimento, o tempo e a transformação dos educadores se transmutaram na discussão sobre sucessão do tempo e mudança em certos modelos teóricos; no terceiro movimento, histórias de vida se transmutaram em trajetórias de vida.

O que, portanto, ocorre quando antropólogos incorporam as narrativas de vida daqueles que estudam? Como lembra Kofes (2001, p. 126), em relação ao seu trabalho, “[...] não sou só leitora e ouvinte das narrativas sobre Consuelo. Também efetuei os trabalhos de mimesis: tudo o que foi aqui escrito é uma narrativa, na justa medida em que conjuga temporalidades dispersas". Também as nossas análises antropológicas abrem uma espécie de tempo emergente. Como qualquer narrativa que se cria, a dos antropólogos não ocorre sem efeitos, permitindo certa transmutação: as menções aos desejos, medos, acusações, fofocas, lembranças de nossos interlocutores, podem se transmutar, por exemplo, em marcadores sociais da diferença, que por sua vez se tornam os vetores que guiam uma análise sobre a intersecção entre sistemas classificatórios e estrutura social; podem também se transmutar em inscrições intersticiais da diferença, que por sua vez se tornam o vetor que guiam a análise sobre transformação e tempo emergente no campo e na escrita antropológica.

O que está em questão não é tanto se a as análises agenciam transformações, pois sempre as fazem. A questão é como operá-las. Manter a proeminência das noções de nossos interlocutores nas nossas análises como uma postura política não se resolve nem pela tentativa de lhes "dar voz", nem pela suposição de que se fala "a partir da perspectiva nativa", pois em ambos os casos seus conceitos, práticas e modelos são inevitavelmente subsumidos por modelos antropológicos. Este é o perigo já apontado por Spivak (2010, p. 79), do “[...] intelectual do Primeiro Mundo que se mascara como um não representante ausente que deixa os oprimidos falarem por si mesmos". O subalterno não pode falar, como mostra brilhantemente, daí a solução inspirada em Jacques Derrida, de se reconhecer que o pensamento é a parte em branco do texto que deve ser confiado ao Outro da história. ${ }^{8}$ 
Os críticos e intelectuais pós-coloniais podem tentar deslocar sua própria produção apenas pressupondo esse espaço em branco inscrito no texto. Tornar o pensamento ou o sujeito pensante transparente ou invisível parece, por contraste, ocultar o reconhecimento implacável do Outro por assimilação. É no interesse de tais precauções que Derrida não invoca que se "deixe o(s) outro(s) falar por si mesmo(s)", mas, ao invés, faz um "apelo" ou "chamado" ao "quase-outro" (tout-autre em oposição a um outro autoconsolidado), para "tornar delirante aquela voz interior que é a voz do outro em nós. (Spivak, 2010, p. 83, grifos da autora)

Ainda que Spivak reafirme a tarefa da mulher intelectual em tornar delirante a voz do outro em nós, ela não avança o argumento sobre como fazê-lo. Trata-se de problema análogo ao que foi posto acima nos seguintes termos: como garantir a proeminência das noções de nossos interlocutores (a voz do outro) nas análises antropológicas? O procedimento inaugurado por Marilyn Strathern (2004) parece uma possível contribuição para tanto, na medida em que renova o empreendimento comparativo na antropologia ao sempre explicitar as aproximações, paralelos e transformações dos conceitos nativos em relação aos conceitos oriundos da teoria, como corpos que se mantêm externos uns aos outros, e cujo encontro provoca novas aberturas, novas conexões. E assim buscou-se fazer neste texto por meio de bifurcações. Não se tratou aqui de "deixar os educadores falarem" a partir da adoção da perspectiva colonial, mas sim de, na companhia de Jucélia, José Luiz, Daniel, Vander, Erika, Clébisom, Erivan, Zuleide e Robson, promover agenciamentos particulares, o tempo emergente aberto pela escrita antropológica.

\section{Notas}

1 Todas as traduções da autora.

2 No Brasil, o texto foi publicado como Ferguson e Gupta (2000).

3 A pesquisa de campo em Recife e Olinda ocorreu em julho de 2005 e de janeiro a julho de 2006. Este artigo é uma versão modificada do texto que foi escrito em 2006 e, logo depois, engavetado por muitos anos. Era preciso mais tempo para amadurecer as reflexões teórico-metodológicas contidas neste argumento. Agradeço a Julio Simões pelo entusiasmo com que sempre recebeu meu material de pesquisa e a autonomia reflexiva que me confiou como orientador à época. Também agradeço ao Núcleo de 
Estudos sobre Marcadores Sociais da Diferença (Numas), da Universidade de São Paulo, que, por meio de um convite para participar da mesa "Desenvolvimento e Pós-Colonialismos" em novembro de 2015, deu-me a oportunidade de revisitar o texto. Por fim, agradeço à Letícia Cesarino, que me ofereceu o mote teórico para reelaborar o artigo de maneira mais aprofundada.

4 Por motivos que deixo claros mais adiante, mantenho os nomes originais dos educadores. Mantenho também a marcação rítmica da fala por meio de reticências, bem como o momento em que aparecem nas gravações, para que se notem os cortes feitos por mim.

5 Barracas são espécies de pequenos armazéns, muito comuns nas comunidades que frequentei em minha pesquisa de campo. Geralmente são espaços dentro das próprias casas, especificamente janelas que são gradeadas, por onde as famílias vendem itens de consumo pessoal.

6 Zuleide de Paula é autora de um livro sobre o bairro de Peixinhos que é objeto de discussão em Morawska Vianna (2007).

7 A disseminação no Brasil se vê pela tradução de Crenshaw (2002), McKlintock (2010) e da já mencionada Brah (2006). Ver Davis (2008) para uma análise a partir da sociologia do conhecimento sobre como a interseccionalidade passou a ser vista como uma das maiores contribuições aos estudos feministas nos últimos anos. Tal proeminência não vem sem dissensos e, nesse sentido, Carbin e Edenheim (2013) são um exemplo de crítica à abordagem.

8 É importante notar que a solução que Spivak (2010) encontra para a impossibilidade de fala do Outro subalterno e, sobretudo, da Outra subalterna, é inspirada em um filósofo europeu, Jacques Derrida, cujo trabalho a autora considera ser útil para aqueles que se situam fora do Primeiro Mundo, uma vez que ele localiza o problema da construção do Outro subalterno não como um problema geral, mas como um problema europeu. Esse argumento lhe parece menos perigoso do que a "transparência autodiagnosticada do intelectual radical do Primeiro Mundo" (Spivak, 2010, p. 60). Para a relação entre o desconstrucionismo de Derrida e a teoria pós-colonial, ver Syrotinski (2007).

\section{Referências}

BHABНA, Homi K. O Local da cultura. Belo Horizonte: Editora da UFMG, 2003.

BOURDIEU, Pierre. Coisas ditas. São Paulo: Brasiliense, 2004.

Esboço de uma teoria da prática. In: ORTIZ, Renato (Org.). Pierre Bourdieu: sociologia. São Paulo: Ática, 1983. p. 46-81.

BRAH, Avtar. Diferença, diversidade, diferenciação. Cadernos Pagu, Campinas, n. 26, p. 329-365, 2006.

BRAH, Avtar; Phoenix, Ann. Ain't I a woman? Revisiting intersectionality. Journal of International Women's Studies, [S.l.], v. 5, n. 3, p. 75-86, 2004. 
BUTLER, Judith. Excitable Speech: a Politics of the Performative. New York: Routledge, 1997.

CARBIN, Maria; EDENHEIM, Sara. The Intersectional Turn in Feminist Theory: A Dream of a Common Language? European Journal of Women's Studies, [S.l.], v. 20, n. 3, p. 233-248, 2013.

CRENSHAW, Kimberlé. Documento para o encontro de especialistas em aspectos da discriminação racial relativos ao gênero, Revista Estudos Feministas, Florianópolis, v. 10, n. 1, p. 171-188, 2002.

. Mapping the Margins: Intersectionality, Identity Politics, and Violence against Women of Color. Stanford Law Review, Stanford, v. 43, n. 6, p. 1.241-1.299, 1991.

. Demarginalizing the Intersection of Race and Sex: A Black Feminist Critique of Antidiscrimination Doctrine, Feminist Theory, and Antiracist Politics. University of Chicago Legal Forum, Chicago, v. 14, p. 538-554, 1989.

DAVIS, Kathy. Intersectionality as buzzword: A sociology of science perspective on what makes a feminist theory successful. Feminist Theory, [S.l.], v. 9, n. 1, p. 67-85, 2008.

FERGUSON, James. The Anti-politics Machine: Development, Depoliticization, and Bureaucratic Power in Lesotho. Minneapolis; London: University of Minnesota Press, 1994.

FERGUSON, James; GUPTA, Akhil. Mais além da 'cultura': espaço, identidade e política da diferença. In: ARANTES; Antonio A. (Ed.).

O Espaço da diferença. Campinas, SP: Papirus, 2000. p. 30-49.

GUPTA, Akhil. Postcolonial Developments: agriculture in the Making of Modern India. Durham \& London: Duke University Press, 1998.

GUPTA, Akhil; FERGUSON, James. Beyond "Culture": Space, Identity, and the Politics of Difference. Cultural Anthropology, [S.l.], v. 7, n. 1, p. 6-23, 1992.

KOFES, Suely. Uma trajetória em narrativas. Campinas: Mercado de Letras, 2001.

MBEMBE, Achille. On the Postcolony. Berkeley; Los Angeles: University of California Press, 2001.

McKLINTOCK, Anne. Couro Imperial: Raça, gênero e sexualidade no embate colonial. Campinas: Editora da Unicamp, 2010.

. Imperial leather: Race, gender and sexuality in the colonial contest. New York: Routledge, 1995. 
MORAWSKA VIANNA, Catarina. Cooperação internacional católica: entre a política dos movimentos sociais e o ativismo da fé em ação. Religião $\mathbf{\delta}$

Sociedade, Rio de Janeiro, v. 35, n. 2, p. 213-248, 2015.

Os Enleios da Tarrafa: Etnografia de uma relação transnacional entre ONGs. São Carlos: EDUFSCar, 2014.

. Em busca de narrativas densas: questões acerca de realidades narrativas, subjetividade e agência social. Cadernos de Campo, São Paulo, v. 16, p. 153-158, 2007.

MOUTINHO, Laura. Diferenças e desigualdades negociadas: raça, sexualidade e gênero em produções acadêmicas recentes. Cadernos Pagu, Campinas, n. 42, p. 201-248, 2014.

MOUTINHO, Laura; LOPES, Pedro; ZAMBONI, Marcio; RIBAS, Mario; SALO, Elaine. Retóricas ambivalentes: ressentimentos e negociações em contextos de sociabilidade juvenil na Cidade do Cabo (África do Sul).

Cadernos Pagu, Campinas, n. 35, p. 139-176, 2010.

PISCITELLI, Adriana. Atravessando fronteiras: teorias pós-coloniais e leituras antropológicas sobre feminismos, gênero e mercados do sexo no Brasil. Contemporânea, São Carlos, v. 3, n.2, p. 377-404, 2013.

. Interseccionalidades, categorias de articulação e experiências de migrantes brasileiras. Sociedade e Cultura, Goiânia, v. 1 1, n. 2, p. 263274, 2008.

SAHLINS, Marshall. O 'pessimismo sentimental' e a experiência etnográfica: por que a cultura não é um 'objeto' em via de extinção (parte I). Mana, Rio de Janeiro: UFRJ, v. 3, n. 1, p. 41-73, 1997.

SCHWARCZ, Lilia. Prefácio: Quando todos os caminhos levam de Belém a São Paulo e vice-versa. In: CANCELA, Cristina Donza; MOUTINHO, Laura; SIMÕES, Júlio Assis (Org.). Raça, etnicidade, sexualidade e gênero em perspectiva comparada. São Paulo: Ed. Terceiro Nome, 2015. p. 7-12.

SIMÕES, Júlio Assis; FRANÇA, Isadora Lins; MACEDO, Márcio. Jeitos de corpo: cor/raça, gênero, sexualidade e sociabilidade juvenil. Cadernos Pagu, Campinas, n. 35, p. 37-78, 2010.

SPIVAK, Gayatri Chakravorty. Pode o subalterno falar? Belo Horizonte: Editora da UFMG, 2010.

STRATHERN, Marilyn. Binary License. Common Knowledge, [S.l.], v. 17, n. 1, p. 87-103, 2011.

. Partial Connections. Walnut Creek: Altamira Press, 2004. 
SYROTINSKI, Michael. Deconstruction and the Postcolonial: at the limits of theory. Liverpool: Liverpool University Press, 2007.

Recebido em 02/10/2017

Aceito em 21/10/2017 